
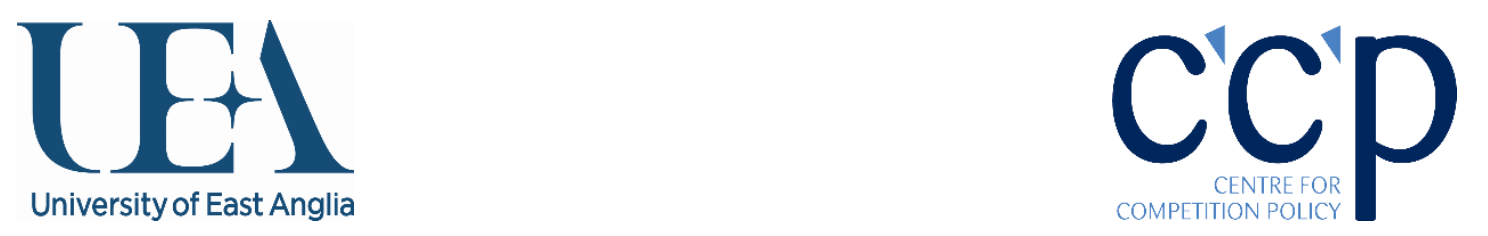

\title{
Cartel enforcement and deterrence over the life of a Competition Authority
}

\author{
Khemla Prishnee Armoogum \\ Competition Commission of Mauritius \\ Stephen Davies \\ Centre for Competition Policy \\ School of Economics \\ University of East Anglia \\ Franco Mariuzzo \\ Centre for Competition Policy \\ School of Economics \\ University of East Anglia \\ CCP Working Paper 17-4
}

\begin{abstract}
This paper searches for evidence that, as a Competition Agency (CA) builds up experience in cartel enforcement, this feeds back into the business community to deter future cartel formation. We present two simple models, focussing respectively on composition and frequency deterrence, which describe how the feedback would work. The ideal outcome is that, over the long-run, the number of cartels detected by a successful CA will follow an inverted U-shaped time path: its propensity to detect increase, but the number of cartels out there to be detected decrease. Empirically, we try to simulate the long-term dimension by using an international panel of CAs. Although comparable data are only available for a relatively short time period (2006-2014) we hope that longer-run effects are captured by including in the panel CAs at very different stages in their life cycles. We find evidence of the predicted inverse $U$ shape, and interpret this as consistent with an increasingly strong feedback from enforcement to deterrence as the CA evolves over the years.
\end{abstract}

Contact Details:

Stephen Davies

S.W.Davies@uea.ac.uk 


\title{
Cartel enforcement and deterrence over the life of a Competition Authority*
}

\author{
Armoogum Khemla Prishnee†, Stephen Davies; and Franco Mariuzzo ${ }^{\ddagger}$
}

\begin{abstract}
This paper searches for evidence that, as a Competition Agency (CA) builds up experience in cartel enforcement, this feeds back into the business community to deter future cartel formation. We present two simple models, focussing respectively on composition and frequency deterrence, which describe how the feedback would work. The ideal outcome is that, over the long-run, the number of cartels detected by a successful CA will follow an inverted U-shaped time path: its propensity to detect increase, but the number of cartels out there to be detected decrease. Empirically, we try to simulate the long-term dimension by using an international panel of CAs. Although comparable data are only available for a relatively short time period (2006-2014) we hope that longer-run effects are captured by including in the panel CAs at very different stages in their life cycles. We find evidence of the predicted inverse $U$ shape, and interpret this as consistent with an increasingly strong feedback from enforcement to deterrence as the CA evolves over the years.
\end{abstract}

Keywords: cartels, cohort effects, competition policy evaluation, deterrence, detection

JEL Classification codes: K21, L44, H11

${ }^{*}$ This paper was presented at 2017 Centre for Competition Policy seminar series. The usual disclaimer applies. The authors wish to acknowledge the financial support from the ESRC Centre for Competition Policy (funding ref: RES-578-28-0002). The article draws on chapters 4 and 5 of Armoogum (2016)'s PhD thesis.

${ }^{\dagger}$ Competition Commission of Mauritius, email: khemla@yahoo.com. The views herein are those of the author and not necessarily those of Competition Commission of Mauritius.

${ }^{\ddagger}$ Corresponding author. School of Economics and Centre for Competition Policy, University of East Anglia, Norwich Research Park, NR4 7TJ, Norwich, United Kingdom, email: s.w.davies@uea.ac.uk.

${ }^{\S}$ School of Economics and Centre for Competition Policy, University of East Anglia, Norwich Research Park, NR4 7TJ, Norwich, United Kingdom, email: f.mariuzzo@uea.ac.uk. 


\section{Introduction}

Over recent years, competition authorities (CAs) and academic researchers have become increasingly interested in the evaluation of competition policy. Inevitably, evaluations are based on counts of activities: the number of cartels or abuses detected and prohibited, and the number of anti-competitive mergers remedied or prohibited in a period of time. However, competition policy entails more than just enforcement; it also involves deterrence. This raises obvious doubts about evaluation methods, which are based solely on counts of cases convicted. For example, suppose that a $\mathrm{CA}$ in a given country records a relatively small number of detected cases. Is this evidence that it is 'weak' both in enforcement and in deterring, or 'strong' because it so effectively deters many potential cartels, leaving few to detect?1 Ideally, an evaluation of policy should aim to measure success in deterrence, as well as purely counting enforcement. But, of course, this is intensely difficult because it requires measuring how the law has impacted on intentions, which have not been materialised into actions.

This paper re-examines the identification problem described by the above weak and poor CA comparison, but within an inter-temporal setting. We explore whether longitudinal evidence on the number of detected cases reveal more about the feedbacks running from success in enforcement to success in deterrence? Ideally, this evidence might be revealed if we have access to longitudinal data for cartel detection over a relatively long time period, by a given CA sufficiently long, that is, for experience at enforcement to accumulate and to grow a reputation, which discourages potential future cartelists. We refer to such evidence as the age profile of cartels convicted over the life cycle of the CA.

We first examine with stylized theoretical models, the two forms of deterrence: frequency,

\footnotetext{
${ }^{1}$ Suppose a population of 100 potential cartels. A strong CA deters $90 \%$ and detects all those that are undeterred, while a weak CA deters none and detects only $10 \%$ of the undeterred. Both CAs would record 10 detected cartels.
} 
which refers to the number of cartels deterred, and composition, which refers to the extent to which fears of detection persuade the cartel to lower its price. We argue that both forms of deterrence should increase over time as the CA becomes increasingly experienced and effective in enforcement. Over the lifetime of the CA, the two effects combine to produce an inverted U-shaped time path. Empirically, we try to estimate the long-term life cycle of a mature CA by international panel analysis of cartel detections. Although the data are only available for a relatively short time period (2006-2014) we capture longer-run effects by including in the panel CAs at very different stages in their life cycle: some are very mature (USA) but some are very young (Pakistan). This necessitates that we apply cohort analysis on our panel. We find evidence of the predicted inverse $\mathrm{U}$, and interpret this as consistent with an increasingly strong deterrence feedback as the CA evolves over the years. Of course, we cannot rule out some alternative explanations, notably that firms become more sophisticated at avoiding detection.

\section{$1.1 \quad$ Literature review}

In recent decades, a body of research has studied alternative methodologies to assess the success of a $\mathrm{CA}$ is in achieving its aims. Among the various methods employed, many are based on counts of observed activities (see Davies and Ormosi (2012) for a survey). For example, simple counting of the number of cartels detected and prohibited, but this approach has been subject to much criticism along the lines described in our opening paragraph (see also Kovacic et al. (2011)).

As Buccirossi et al. (2014) note, the most effective competition policy regime is one in which the competition authority achieves total deterrence and, hence, never has to block a merger, never has to uncover a cartel or any other anticompetitive agreement, and never has to condemn a firm for abusing its dominant position. In an ideal regime firms do not dare 
to propose an anticompetitive merger, do not attempt to form a cartel, and never enter into an anticompetitive agreement.

Non-detection and deterrence are, by their nature, the two big unknowns, and problems of quantification are obvious. Rather more progress has been made on estimating the detection rate than the deterrence rate. The first major study was by Bryant and Eckard (1991), who use a model of statistical birth and death process to estimate that the probability of getting caught for price fixing conspiracies is between $13 \%$ and $17 \%$ a year in the US between 1961 and 1988. Using the same methodology Combe et al. (2008) later estimate the probability of a cartel getting caught in the EU to be about $13 \% \mathrm{~L}^{2}$ More recently, drawing from a capturerecapture analysis, Ormosi (2014) estimates time-dependent cartel discovery rates, while allowing for heterogeneity across firms. His results suggest that the European Commission's detection rate was 15\%-20\% between 1967 and 2007, which again is in line with the figures above. On deterrence we have far less to go on. Although there are extensive literatures on various aspects of deterrence, for example, the optimal deterrent effect of financial sanctions (see Connor (2007)), very little research has been devoted to assessing impact on deterrence, either qualitatively or quantitatively.

There is a growing indirectly related literature. For example, Miller (2009) assesses the qualitative impact on deterrence of the introduction of the leniency programme in 1993 and finds evidence of increased cartels' detection rate. Clougherty et al. (2016) identify the lagged deterrent effect on frequency of mergers of the European Commission's interventions on previous cases. The Agencies themselves have commissioned various survey studies (based on the opinions of competition lawyers and the firms themselves), to try and figure out how many cartels are deterred for every case that is detected. For example, in Office of Fair Trading (2007), a multiplier of 5:1 is cited. Buccirossi et al. (2011) developed the Competition

\footnotetext{
${ }^{2}$ Connor and Lande (2011) provide an exhaustive survey of these and other estimates of the rate of detection.
} 
Policy Indexes (CPIs), a set of indicators of the quality/intensity of competition policy to measure the deterrence effects of a competition policy in a jurisdiction. In investigating how anti-cartel enforcement deters consumer harm. Finally, in two recent studies, Davies et al. (2017) estimate that (i) the harm detected by the CA really is only the tip of the iceberg, accounting for only a small fraction (at most one sixth) of total potential harm; (ii) deterrence accounts for at least $50 \%$, probably much more, of all potential cartel harm in the population, and (iii) undetected harm is at least twice as large as detected harm. In Bos et al. (2017) standard cartel theory is used to show that, if enforcement has a deterring effect, it is most pronounced for low and high overcharge potential cartels. This is confirmed empirically by a historical comparison of legal and illegal cartels. However, none of these studies addresses

the central issue of the current paper how the quantity of cartel enforcement evolves in the long run, given deterrent feedbacks.

In the next section, we present two models of cartel deterrence - first for composition and then for frequency; both point to an inverse $\mathrm{U}$ shape in the number of detections. In section 3 . this hypothesis is tested empirically on a pooled sample of over 30 countries observed over the years 2006-14. Section 4 concludes.

\section{The model}

In this section we present a theoretical model, which captures in a simple intuitive manner the ways in which the number of cartels convicted by a CA might evolve over the lifetime of a CA. In particular, we are interested in the possibility of an inverted U-shape, as that pattern would suggest that number of convicted cases might eventually decline for mature authorities.

We distinguish between composition-based and frequency-based and deterrence. The former refers to the case where, although the cartel is not deterred from forming, it chooses 
to change its behaviour (typically, through reducing price) so as to avoid being caught; the latter refers to the case where a potential cartel is deterred from even forming.

The investigation probability: The CA receives and monitors various signals from different players in the economy in the form of complaints from customers, rivals or other trade sources. These sources of complaint are combined in our model into a single signal and are assumed to increase with the price set by the cartel, and with the 'effort', $g$, which the CA chooses to expend on investigation of cartels. For simplicity, we assume linearity:

$$
\tau(p)=g p, \text { with } 0 \leq g, p \leq 1
$$

The cartelists are assumed to know this probability distribution.

The conviction probability: Once the firms are investigated, they are successfully prosecuted with probability $\gamma$, with $0<\gamma \leq \gamma \leq 1$. The parameter $\gamma$ is treated as exogenous, with value known to the firms and to the CA.

It follows that the probability of conviction, $P C$, is the product of the probability of investigation, and the probability of conviction conditional on investigation:

$$
P C=\tau \gamma
$$

If convicted, the cartel is charged (via a fine or/and imprisonment) an amount $F$, so the expected fine faced by a cartel is given by:

$$
f \equiv E(\tilde{f})=\tau(p) \gamma F
$$

and $0<F \leq \frac{1}{4}$ is a fixed fine, which is bounded to the maximum monopoly profit, as it should not be too high to induce exit. 


\subsection{Composition deterrence}

We first consider a single cartelised market. Both firms and the CA are risk-neutral agents. The CA's objective is to maximise consumer welfare, which, in this context, means limiting cartel abuse. The CA's budget is allocated by the government and is independent of its

performance. The model is based on a two-stage game. In stage one, the CA chooses the effort it devotes to investigating cartels, and this determines the probability that the cartel is investigated. In stage two, the cartelists take this uncertain probability into account when setting output to maximise their expected profit. We examine how deterrence changes, in the form of the price set, as the CA becomes more efficient in convicting cartels.

Firms' behaviour Cartelists are risk neutral and maximise their joint expected profit $E(\tilde{\pi})$. The inverse demand function for a given market is deterministic and given by $p=$ $1-q$. For expositional simplicity, and without loss of generality, we set the marginal cost of production to be zero. The expected profit function for the cartel is then given by:

$$
\pi \equiv E(\tilde{\pi})=(1-q) q-(1-q) g \gamma F
$$

Optimal output for the cartel given CA's 'effort' is then:

$$
q(g)=\frac{1+g \gamma F}{2}
$$

Thus, if the CA increases its effort $g$, the cartel will increase its output and hence lower its price.

Competition authority's problem In deciding how much effort to expend, the CA is assumed maximise consumer welfare, $w$, net of its enforcement costs. It is assumed that these costs are a strictly convex function of the effort $g^{2} / 2$, because an investigation becomes 
increasingly costly once the relatively easy first steps have been completed. Net welfare is then

$$
\begin{aligned}
w(q(g)) & =\int_{0}^{q(g)}(p(q)-p(g)) d q-\frac{g^{2}}{2} \\
& =\int_{0}^{q(g)}((1-q)-(1-q(g))) d q-\frac{g^{2}}{2} .
\end{aligned}
$$

Substituting $q(g)$ from Equation 5 in Equation 6 and integrating yields:

$$
w(q(g))=\frac{(1+g \gamma F)^{2}-4 g^{2}}{8}
$$

From this, solving for optimal $g$, yields

$$
g^{*}=\frac{\gamma F}{4-\gamma^{2} F^{2}}
$$

Then, substituting Equation 8 into Equation 5, the optimal quantity $q^{*}$ is

$$
q^{*}=\frac{2}{4-\gamma^{2} F^{2}}
$$

Finally, substituting Equations 8 and 9 into Equation 1, the optimal probability of detection is:

$$
\tau^{*}=\frac{\gamma f\left(2-\gamma^{2} F^{2}\right)}{\left(4-\gamma^{2} F^{2}\right)^{2}},
$$

and it follows that the optimal probability that a cartel is convicted is

$$
P C^{*}=\tau^{*} \gamma=-\frac{\gamma^{2} F\left(\gamma^{2} F^{2}-2\right)}{\left(\gamma^{2} F^{2}-4\right)^{2}} .
$$

Proposition 1. As the CA gains more experience, (i.e. $\gamma$ rises), the detection probability 
$\left(\tau^{*}\right)$ rises. This results in an unambiguous increase in the probability of conviction.

Proof. from Equation 10: $\frac{d \tau^{*}}{d \gamma}=\frac{F\left(\gamma^{4} F^{4}+6 \gamma^{2} F^{2}-8\right)}{\left(\gamma^{2} F^{2}-4\right)^{3}}>0$, and as both $\gamma$ and $\tau^{*}$ increase, from Equation 11: $\frac{\partial P C^{*}}{\partial \gamma}=\frac{4 \gamma F\left(3 \gamma^{2} F^{2}-4\right)}{\left(\gamma^{2} F^{2}-4\right)^{3}}>0$

The intuition is that an increase in the efficiency of conviction is equivalent to an increase in the expected fine, prompting an increase in output, $\frac{\partial q^{*}}{\partial \gamma}=\frac{4 \gamma F^{2}}{\left(\gamma^{2} F^{2}-4\right)^{2}}>0$ and subsequent drop in prices. This also yields:

Corollary 1. Increased CA experience leads to increased output and lower price, and thus increased consumer welfare: $\frac{d w^{*}}{d \gamma}=\frac{\gamma F^{2}}{\left(\gamma^{2} F^{2}-4\right)^{2}}>0$ : thus composition deterrence.

To summarise, the CA sets its investigation effort so as to maximise consumer welfare, net of its costs. This determines the probability of triggering a cartel investigation $(\tau)$, which depending on the CA's efficiency determines the probability that the cartel is convicted. If effort is optimised, it is shown that an increase in the efficiency (or an increase in the fine) leads to increased effort, and probabilities of investigation and conviction. This results in a lower cartel price and increased consumer welfare. In spite of its static nature this model provides straightforward predictions for how things might change over time as the CA gains more experience. In general, we would expect any CA to gather more experience over time, and in this can be modelled here simply as increased efficiency in detection. If so, the above comparative statics with respect to the probability of a successful investigation have obvious inter-temporal implications. With the passage of time, as the CA gains experience, its detection efficiency increases. This causes it to increase its effort and the probabilities of investigation and conviction will both increase. Hence, the probability that a given cartel will be convicted increases over the lifetime of the CA - even although the cartel also continually decreases its price. We return to these results below, and we also acknowledge that identification could be a problem if there are systematic changes in the CA's budget over time. A 
CA with a relatively generous budget is more likely to have the necessary resources to train its staffs and hence exploit its greater potential efficiency in detecting more cartels. This suggests that inter-temporally, $\gamma$ may not necessarily always increase at the same rate over time. More realistically, this could be reversed, or the rate of increase in efficiency slowed, in times of tightened CA budget constraints, and vice versa of course. Thus, although it is reasonable to assume that in general a $\mathrm{CA}$ may acquire increasing experience over time, in the presence of limited financial resources, the rate of increase may also be sensitive to changes in its budget allocation. Indeed, in extreme cases of extreme budget cuts, experience may even decay. We will capture this possibility in the econometric estimation in Section 3 .

\section{$2.2 \quad$ Frequency deterrence}

We now turn to the second form of deterrence: where the fear of detection and punishment deters cartels from forming, or persuades them to disband where they already exist. We

extend the single-market model to a multi-market economy. We continue to denote with $P C$ the probability that a given cartelised market is convicted, but we now explore the number of cartels which are alive.

In the economy there are $M$ markets, which are either cartelised or deterred from cartelising. Denoting the number of cartels deterred in period $t$ by $D(t)$, the expected number of convicted cartels, $E N C(t)$, is:

$$
E N C(t)=P C(t)(M-D(t))
$$

Deterrence is assumed to be increasing in $P C(t)$ : the higher is the probability of conviction, the more cartels are deterred from forming, thus $d D / d P C>0$.

\section{Special case}

Under fairly weak assumptions, Equation 12 will lead to an inverse U shaped relationship 
of $E N C$ to time. For example, for expositional simplicity, assume

$$
D(P C(t))=\beta P C(t)
$$

where $\beta>0$ measures the strength of the deterrence effect. Substituting Equation 13 into Equation 12, gives

$$
E N C(t)=P C(t)(M-\beta P C(t))
$$

Proposition 2. The expected number of convicted cartels is a quadratic function of PC $(t)$, with a maximum at $P C=M / 2 \beta$. Since $P C(t)$, is continuous and strictly increasing in $t$ (in Proposition 1 it was increasing in the conviction probability, there denoted with $\gamma$ ), this means that over time ENC(t) will first increase up some maximum and thereafter decrease.

Proof. $d E N C / d P C=M-2 \beta P C=0$ where $E N C=M / 2 \beta$ and $\frac{\partial^{2} E N C}{\partial P C^{2}}<0$ and any higher order derivative is zero.

Alternatively, if deterrence were to be a different function of conviction, for example of the type $D(P C(t))=\beta_{1} P C(t)\left(\beta_{2}-\beta_{3} P C(t)\right)$, with all $\beta s>0$, then the resulting function would be cubic, which would first increase, then decrease and then increase again. This example of cubic function would give maximum at an intermediate level of time, and possibly a second maximum beyond a reasonable support of time. In our empirical section we will test for various functional forms of unobserved deterrence.

\section{Empirical analysis}

The central hypothesis to test from these simple theoretical models is that the number of cartels convicted will typically rise (potentially for many) years of the CA's lifetime, but that at some point it will hit a ceiling and thereafter decline. The period of decline can be 
interpreted as a maturity stage, in which the fruits of deterrence become dominant.

Ideally, the necessary data would be longitudinal on cartel detection from the time of the CA's establishment to date. Additionally, we would have information on control variables over the same period. From the previous literature and our theoretical model these other potential explanatory variables might include potential resource constraints, penalties, and legal/institutional features of the jurisdiction which might affect the efficiency of CA. Given the longevity of many CAs around the world, this places heavy demands on data and in the event we have been able to collect comparable data for a relatively short recent time period. Ideally, tests of the longer term life cycle hypotheses envisaged here require much longer time periods.

Our solution is to employ an international panel, which although it only covers the relatively short recent period, 2006-14, includes many CAs from various countries, observed at very different stages in their life cycles. Thus the cross-section dimension provides the equivalent of a longer-term supplement to the shorter time series in real time. However, because this entails an inevitable heterogeneity, which may not all be controlled for with country fixed effects, we also employ an age-period-cohort approach (see below).

The panel includes 34 competition authorities from 33 countries (plus the EU) over the period 2006-2014 $!^{3}$ These are all the countries with at least six years of country data, with exception of Chile, available from 2008, and Pakistan, available from 2010. Data are extracted from GCR enforcement reports.

Because most of the CAs introduced cartel law before the start of our panel period, they each enter the panel at different ages. This means that there are, in effect, three inter-temporal dimensions, and for that reason our empirical model is an application of age-

\footnotetext{
${ }^{3}$ The jurisdictions are Australia, Austria, Belgium, Brazil, Canada, Chile, Czech, Denmark, EU, Finland, France, Germany, Greece, Hungary, Ireland, Israel, Italy, Japan, Korea, Lithuania, Mexico, Netherlands, New Zealand, Norway, Pakistan, Poland, Portugal, South Africa, Slovakia, Spain, Sweden, Switzerland, UK and US (DoJ).
} 
period-cohort analysis. The main focus is to determine the age profile of cartel prosecutions, but because CAs have established their cartel law at different times, they are expected to belong to different cohorts. Given this feature of the data it is important that the age profile is not confounded with the cohort effect. In addition, as in any panel, there are time effects, which are the consequences of influences that vary through time, e.g. the financial crisis that occurred in 2008 and might have impacted on the number of cartel cases.

The age-time-cohort analysis serves as a methodology that one can use to filter the age profile from the other two confounding factors (Yang et al. (2004)). In this context, cohort effects are the consequences of a group of authorities setting up in particular periods and sharing a specific event together during a particular time span, e.g. change in trade or competition policy (commonality of competition laws), free trade between countries. All CAs that established their cartel law in the same period might share common features.

In most applications, an arbitrary five-year interval is used to define cohorts (see Levin and Stephan (1991)). But, since we have key dates where there have been main changes in the global laws and regulations with CAs sharing the common likelihood of experiencing the changes, the age data is grouped into the following four cohorts:

- Cohort 1 Before 1957 (the EC treaty Treaty Of Rome)

- Cohort 2 Between 1958 and 1986 (after the treaty but before the EU single Act)

- Cohort 3 Between 1987 to 1996 (after the EU single Act but before the launching of WTO's competition project)

- Cohort 4 After 1997 (launch of the WTO competition project).

For example, UK established its first cartel law in 1956, so it is allocated to Cohort 1, and in the first observation year, 2014, its CA's age is 58.4

\footnotetext{
${ }^{4} \mathrm{~A}$ well-known problem that arises when using the age-period-cohort model is that of identifiability. This
} 
The model to be estimated for competition authority at year $t \in(2006, \cdots, 2014)$ is:

$$
\begin{aligned}
\ln \# \text { carte }_{i t}= & \theta_{0}+f\left(\text { age }_{i t} \mid \theta_{1}\right)+\theta_{2} \text { leniency }_{i t}+\theta_{3} \ln \# \text { merger }_{i t}+\theta_{4} \ln \text { fines }_{i t}+\theta_{5} \ln \text { prison }_{i t} \\
& +\theta_{6} \text { commonlaw }_{i}+\theta_{7} \text { prosecutorial }_{i}+L .\left(\ln \text { budget }_{i t} \mid \theta_{8}\right)+u_{i}+\vartheta_{i t} .
\end{aligned}
$$

In the notation above, ln \#cartel is the natural log of the number of prosecuted cartels. Since the above theory does not provide precise predictions about the exact mathematical form of the age profile, except that it should allow for the possibility of an inverse U-shape profile, the model is tested with three alternative polynomials - quadratic, cubic and quartic, and thus indicated in the econometric equation with the general functional form $f\left(a g e_{i t} \mid \theta_{1}\right)$. Inclusion of higher order polynomials would complicate the analysis and provide less robust results because of quasi-multicollinearity, and most importantly, it would make little economic sense. Our a priori preference is for the cubic since it is the most parsimonious functional form allowing for a non-symmetric inverse U-shape. The term $u_{i}$ is the unit-specific unobserved heterogeneity that differs across CAs and $\vartheta_{i t}$ is the remainder idiosyncratic disturbance. The other explanatory variables are defined in Table 1 and can be grouped in three broad categories.

Budget Although we capture the profile of the CA mostly by the experience acquired over time, experience will also depend on the depth of the CA's activity, i.e. its budget. A generous budget enables a CA to more effectively enforce its law, train its staff and engage in advocacy. It is normally very costly to run a cartel investigation, given that it may take many years to gather evidence and conclude the prosecution. However, the impact of this variable may not be straightforward. First, there are potentially both positive and negative

occurs due to the exact relationship between the three variables (cohort-period-age). It is impossible to empirically deal with one without also dealing with the others given their closely interrelated effects. To solve for the identification problem, we use the same approach used by Levin and Stephan (1991) and (Hall et al. 2007, p.4). The parameters are restricted by omitting one of the cohort dummies and one of the year dummies to break the exact collinearity. 
impacts on the number of prosecuted cartel cases. While, a higher budget is likely to enable the $\mathrm{CA}$ to convict more cartels, it can also help a CA to be more efficient in deterring cartels (perhaps by engaging in more aggressive compliance programmes) and hence reduce the number of cartels available to be convicted. Second it is possible that budget may be endogenous: for example, while budget can influence the number of prosecuted cartels, the latter can also have a feedback impact on the budget to be allocated to the CA. However, this endogeneity issue is hopefully avoided or mitigated as we posit that the relationship runs from lagged budget, denoted above by $L$. $\left(\ln b_{u d g e t} \mid \theta_{8}\right)$. In our estimates we use a lag of order two, so as to account for the time required by the CA to detect, investigate and then convict the cartels.

Merger cases In most countries, merging firms are obliged to notify the CA if the merger exceeds a certain threshold. The CA then has no choice but to go through every merger case notified (Phase I) and launch investigations (Phase II) if need be. Merger referrals can therefore be considered to be largely exogenous to the CA. Since the CA operates within human and financial constraints, the number of merger cases referred to the CA might negatively impact on its ability to convict cartels. On the other hand, if the CA has a sufficiently generous budget, merger cases are unlikely to have any impact on the number of convicted cartels.

Punishments A number of many early studies (Breit and Elzinga (1973), Posner (1985), Shavell (1985) and Werden et al. (2011)) found that monetary sanctions are best ways to deter cartels. Moreover, years of imprisonment give an indication to firms of what they risk if they are caught to be guilty when engaged in cartels. The higher is the maximum number of years of imprisonment that firms risk, the less likely they are to engage in cartels. Equation 4 in the previous section clearly demonstrates how an increase in the level of punishment impacts negatively on the level of profit of cartels. This consequently causes firms to reduce their prices so as not to be detected. 
Leniency policy Leniency policy is now the most important tool either for detecting cartels or for developing the necessary evidence to convict them (Werden et al. (2011), Bos (2006) and Motta and Polo (2003)). Firms will come forward under the leniency program only if their chance of being successfully prosecuted is sufficiently high (Chang and Harrington (2008)). Leniency is believed to increase the rate of detection at substantially lower cost, so that enforcement resources are saved $(\operatorname{Bos}(2006)$, Miller (2009)). At the early years of the adoption of the leniency policy, a positive relationship between leniency and convicted cartel cases can be expected. On the other hand, if the leniency policy is successful in deterring cartels, it can be expected to be negatively related to the number of convicted cartel over time. Miller (2009) empirically theoretically found that the number of discoveries increases immediately following the leniency introduction and then falls below pre-leniency levels: 5 Therefore, leniency policy can be expected to have both a positive or/and negative influence on the cartel activities of a CA over time.

Legal system: Common law versus civil law The type of legal system adopted by a country may also affect the number of cartels convicted. Common law regimes give more rulemaking powers to the judiciary, while civil law regimes reserve greater power to the legislature giving less discretion to the judiciary (Dainow (1966)). Posner (1973) has claimed that the common law system is superior, largely because it can act more like a market in adapting to change. Others support the legal certainty provided by a civil code. There is no a priori expectation of which is better and the benefits of each may be context-specific. We therefore adopt no prior on whether common law should be better or worse for competition policy in deterring cartels.

Agency design The broad design of the set of institutions responsible for evidence gathering and decision making in competition enforcement is also considered. Following Fox ${ }^{5}$ Cartel detection rate increased by about $62 \%$ and that the rate of cartel formation fell by about $59 \%$ between 1985 and 2005 after leniency policy was introduced. 
and Trebilcock (2012), three basic institutional models are identified:

- judicial, if the competition agency must go to court for enforcement

- bifurcated, if the agency goes to a specialised tribunal for enforcement

- integrated, if a commission within the agency makes the first-level adjudication.

These classifications embrace another important institutional feature, which is the prosecutorial (or adversarial) versus the inquisitorial approach. The first two are naturally prosecutorial, while the third is naturally inquisitorial, so we combine judicial and bifurcated agencies to identify prosecutorial systems. This dichotomy is used in this study. We have no priors on which is superior in this context. The definitions and data sources of these variables are shown in Table 1 and the pooled summary statistics are documented in Table $\left.2\right|^{6}$

[Table 1 about here.]

[Table 2 about here.]

\subsection{Results}

Equation 15 has been estimated using the maximum likelihood random effects estimator (MLREE).7 The main focus of our analysis is on the functional form of the age variable. Columns (i)-(iii) in Table 3 report the quadratic, cubic and quadric forms. Column (iv) documents the results for the cubic, but without the budget variable. Our preferred equation amongst (i)-(iii) is selected based on the Akaike Information Criterion (AIC) test..$^{8}$ As can

\footnotetext{
${ }^{6} \mathrm{~A}$ small amount of interpolation was required for missing years of some independent variables. Also, GCR did not report information for Slovenia for 2012, 2013 and 2014.

${ }^{7}$ Experiments were also conducted using count models such as the Poisson and negative binomial, but the MLREE, was preferred as it produced more robust results.

${ }^{8}$ The Akaike Information Criterion (AIC) test measures the relative quality of statistical models for a given set of data. It also deals with the trade-off between the goodness of fit of the model and the complexity of the model. The AIC is preferred to the Bayesian Information Criterion (BIC) as choice criterion on the grounds that including more parameters is better than omitting significant parameters.
} 
be seen, the cubic (column (ii)) is preferred since it has: (a) the lowest AIC value, and (b) the highest joint significance of the age variables.

[Table 3 about here.]

Figure 1 confirms that the data follow an inverted $U$ shape, and this is clearly not symmetric, in that the rate of decline after the peak is only very moderate, compared to the slope of the curves pre-peak. This is an important advantage of the cubic over the quadratic, which would have imposed symmetry. On the other hand, the cubic is preferred to the quadric in that the cubic is sufficient to capture the underlying pattern in the data with one fewer explanatory variable.

[Figure 1 about here.]

In terms of the central hypothesis of the paper, this does provide evidence consistent with the interpretation of the CA's age profile as a result of an interaction between detection efficiency and increasing deterrence. As a CA acquires experience and becomes more efficient in convicting cartels, it produces frequency deterrence of cartelised behaviour. As the detection rate further increases, this reinforces the deterrent effect. The fact that a cubic, rather than a simple quadratic, fits best can be explained by the shape of the curve after the turning point (which occurs at age $=44$ ). The figure shows that there is a downturn, but only very slight - more like a flattening off into a plateau. The implication is that the deterrent effect is sufficiently strong to balance increased efficiency in detection, but not sufficiently strong to seriously reverse the trend in the number of cases detected.

Turning to the results on the other explanatory variables, as shown by Figure 1, we find that cohorts do impact on the number of convicted cartels over time: those CAs having introduced cartel law in the years following the creation of the European Community (now Union) displaying the highest detection rates, holding all else constant, although the differences between cohorts are not large. 
The CA's budget has a positive role in determining the number of convicted cartels, and as expected, this effect is lagged: a $1 \%$ increase in budget two years previously will lead to an increase of $0.35 \%$ in the number of cartels detected. This lag is plausible since cartel investigations are normally very time consuming, Interestingly, when budget is excluded from the model, the remainder of the equation, including importantly the age coefficients remains remarkably robust (column (iv) in Table 3. It appears then that the stylized time paths depicted in Figure 1 are not materially sensitive to systematic changes in the budget allocated to the CA over its lifetime.

Results on the other explanatory variables are mainly as expected and significant. Amongst the policy variables, leniency programmes appear to have led to major increases (in the order of nearly $150 \%$ ) in the number of convicted cartels. This confirms the effectiveness of leniency programmes around the world. Also confirming the theory in our model, there is evidence that punishments, both in terms of imprisonment and fines, do deter cartelised behaviour: the level of fines and maximum years of imprisonment both lead to reduced cartel activity, but the coefficient on prison is only weakly significant.9 The types of law adopted by a country, as well as the type of institutional design are also shown to have an effect on the number of convicted cartels. CAs functioning in countries adopting a civil law tend to have more convicted cartels than those in countries which follow common law. CAs adopting a prosecutorial law are likely to convict more cartels than those adopting an inquisitorial approach. The one counterintuitive result concerns the positive impact of merger activity: a $1 \%$ increase in number of mergers increases the number of cartels prohibited by $0.15 \%$. We have no plausible explanation for this result.

\footnotetext{
${ }^{9}$ These findings confirm the theories of Breit and Elzinga (1973), Posner (1985), Shavell (1985), Werden et al. (2012).
} 


\section{Conclusions}

This paper attempts to add to the currently sparse evidence of cartel deterrence. The central idea is that over its lifetime a CA will build up its experience and become increasingly effective at detecting cartels. The successes of its enforcement activities will feedback to changes in the behaviour of the business community: some cartels will no longer be formed, and those that do may elect for less pronounced/conspicuous overcharges. We portray these effects using models of composition and frequency deterrence, in which a competition authority administers a deterrence based-competition policy in the presence of uncertainty. These provides a theoretical understanding of how the number of detected cartels might evolve over the age profile of the CA: while increasing detection efficiency pushes up the probability that a given cartel with be detected, the deterrence effects that this stimulates will begin to dampen the number of cartels formed. The outcome, as reflected in the age profile of the number cartels detected, then depends on the relative magnitudes of enforcement efficiency and the deterrence effects. Eventually, it may be that the deterrence effect outweighs detection efficiency, and the number of convicted cases may fall. At the least, this should result in an eventual slowing in the growth of detections, and it may be that eventually there is a downturn, with the age profile of detected cases portraying an inverse U-shape.

Empirically, lack of long-run data availability prevents any direct tests of this hypothesis

for individual countries. However, an international panel analysis over recent yeas which includes different CAs observed at very different stages in their lifetimes provides a plausible way of introducing a pseudo long term dimension to the empirics. Allowing for different cohorts of CAs should enable the panel to identify different segments of the underlying long-term curve. Results are encouraging. It appears that the best fit is achieved by an underlying cubic age profile, in which the number of detections first increases sharply before slowing down, then levelling off and even slightly declining. The turning point occurs roughly 
44 years after the first introduction of the cartel law. While the main focus of the paper concerns the age profile, a number of other results confirm positive roles for the CA's budget, leniency programmes, the deterrence effects of penalties, and the nature of the jurisdiction's legal system.

Notwithstanding the positive results of the paper, further research is clearly called for. Our evidence is only indirect and other interpretations are clearly possible; for example, increasing sophistication of cartels in avoiding detection could lead to similar age profiles. Nevertheless, in coming decades all CAs will move into different stages of their life cycles. As more data accumulates, in-depth long-term studies of individual countries should be possible, and more evidence will emerge on only recently established authorities outside the developed world. 


\section{References}

Armoogum, P. K. (2016). Assessing the comparative performance of competition authorities. $\mathrm{PhD}$ thesis, University of East Anglia.

Bos, I. (2006). Leniency and cartel size: a note on how self-reporting nurtures collusion in concentrated markets.

Bos, I., Davies, S., Harrington, J., and Ormosi, P. (2017). Does enforcement deter cartels? a tale of two tails. Available at SSRN: https://ssrn.com/abstract=2471425orhttp: //dx.doi.org/10.2139/ssrn.2471425.

Breit, W. and Elzinga, K. G. (1973). Antitrust penalties and attitudes toward risk: An economic analysis. Harvard Law Review, pages 693-713.

Bryant, P. G. and Eckard, E. W. (1991). Price fixing: the probability of getting caught. The Review of Economics and Statistics, pages 531-536.

Buccirossi, P., Ciari, L., Duso, T., Spagnolo, G., and Vitale, C. (2011). Measuring the deterrence properties of competition policy: The competition policy indexes. Journal of Competition Law and Economics, 7(1):165-204.

Buccirossi, P., Ciari, L., Duso, T., Spagnolo, G., Vitale, C., et al. (2014). Deterrence in competition law. In The Analysis of Competition Policy and Sectoral Regulation, pages $423-454$.

Chang, M.-H. and Harrington, J. E. (2008). The impact of a corporate leniency program on antitrust enforcement and cartelization. Technical report, Working papers//the Johns Hopkins University, Department of Economics. 
Clougherty, J. A., Duso, T., Lee, M., and Seldeslachts, J. (2016). Effective european antitrust: Does ec merger policy generate deterrence? Economic Inquiry, 54(4):1884-1903.

Combe, E., Monnier, C., and Legal, R. (2008). Cartels: The probability of getting caught in the european union.

Connor, J. M. (2007). Optimal deterrence and private international cartels.

Connor, J. M. and Lande, R. H. (2011). Optimal cartel deterrence: An empirical comparison of sanctions to overcharges. Unpublished.(August 24, 2011).

Dainow, J. (1966). The civil law and the common law: Some points of comparison. The American Journal of Comparative Law, pages 419-435.

Davies, S., Mariuzzo, F., and Ormosi, P. (2017). Quantifying the deterrent effect of anticartel enforcement. Available at SSRN: https://ssrn.com/abstract=2960614orhttp: //dx.doi.org/10.2139/ssrn.2520014.

Davies, S. W. and Ormosi, P. L. (2012). A comparative assessment of methodologies used to evaluate competition policy. Journal of Competition Law and Economics, 8(4):769-803.

Fox, E. M. and Trebilcock, M. J. (2012). The design of competition law institutions: global norms, local choices. Oxford University Press.

Hall, B. H., Mairesse, J., and Turner, L. (2007). Identifying age, cohort, and period effects in scientific research productivity: Discussion and illustration using simulated and actual data on french physicists. Econ. Innov. New Techn., 16(2):159-177.

Kovacic, W. E., Hollman, H. M., and Grant, P. (2011). How does your competition agency measure up? European Competition Journal, 7(1):25-45. 
Levin, S. G. and Stephan, P. E. (1991). Research productivity over the life cycle: Evidence for academic scientists. The American Economic Review, pages 114-132.

Miller, N. H. (2009). Strategic leniency and cartel enforcement. The American Economic Review, 99(3):750-768.

Motta, M. and Polo, M. (2003). Leniency programs and cartel prosecution. International journal of industrial organization, 21(3):347-379.

Office of Fair Trading (2007). The deterrent effect of competition enforcement by the OFT. A report prepared for the OFT by Deloitte, OFT962.

Ormosi, P. L. (2014). A tip of the iceberg? the probability of catching cartels. Journal of Applied Econometrics, 29(4):549-566.

Posner, R. A. (1973). An economic approach to legal procedure and judicial administration. The Journal of Legal Studies, 2(2):399-458.

Posner, R. A. (1985). An economic theory of the criminal law. Columbia law review, 85(6):1193-1231.

Shavell, S. (1985). Criminal law and the optimal use of nonmonetary sanctions as a deterrent. Columbia Law Review, 85(6):1232-1262.

Tetley, W. (1999). Mixed jurisdictions: Common law v. civil law (codified and uncodified). La. L. Rev., 60:677.

Werden, G. J., Hammond, S. D., and Barnett, B. A. (2011). Deterrence and detection of cartels: Using all the tools and sanctions. The Antitrust Bulletin, 56(2):207-234.

Werden, G. J., Hammond, S. D., and Barnett, B. A. (2012). Deterrence and detection of cartels: Using all the tools and sanctions. Antitrust Bulletin, 56(2). 
Yang, Y., Fu, W. J., and Land, K. C. (2004). A methodological comparison of age-periodcohort models: The intrinsic estimator and conventional generalized linear models. Sociological methodology, 34(1):75-110. 


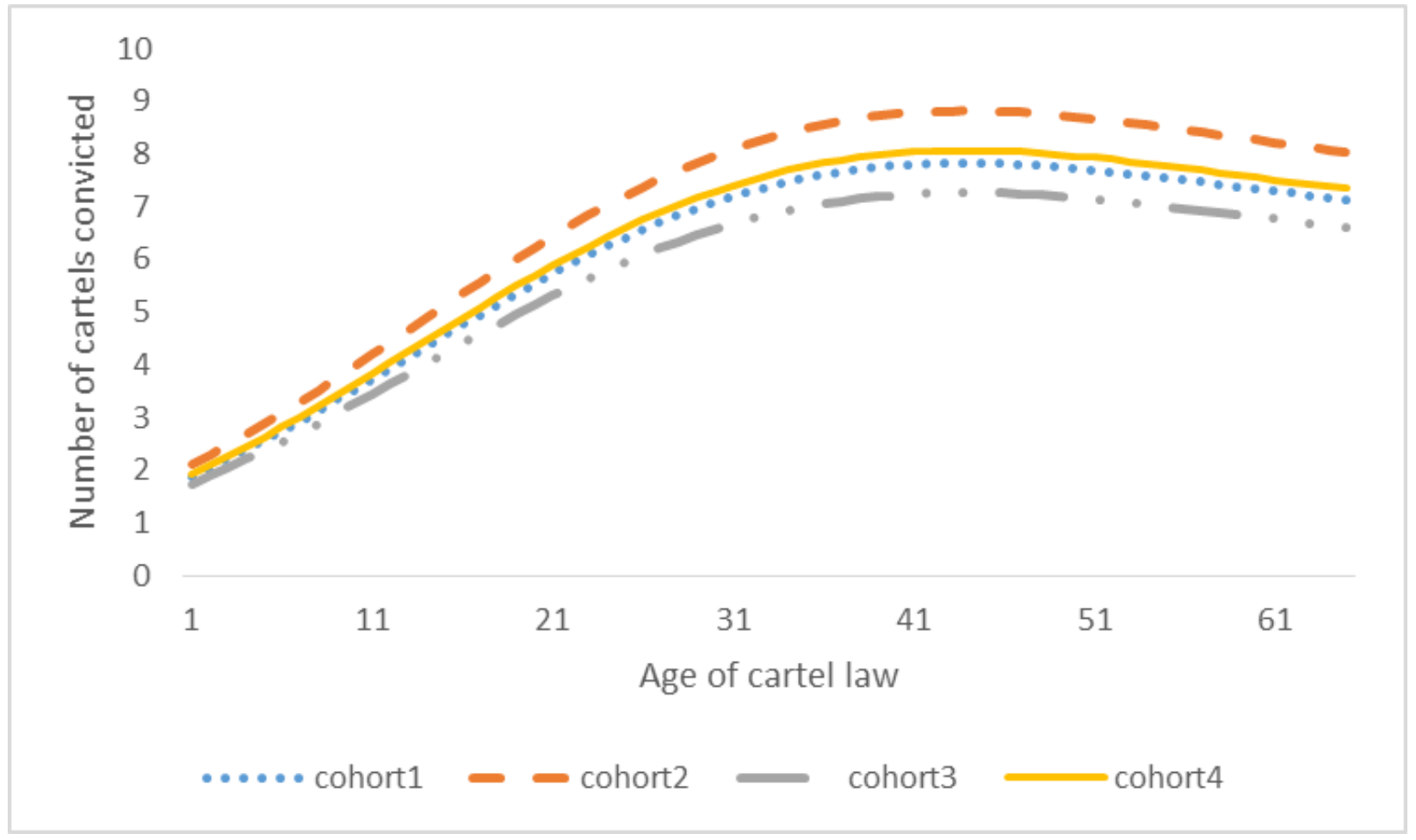

Figure 1: shows the predicted cubic age profile of convicted cartels by CA for each cohort, holding the other explanatory variables constant at sample mean values 
Table 1: Definition of variables and data sources (yearly data by CA)

\begin{tabular}{|c|c|c|c|}
\hline Variable & Definition & Form & Source \\
\hline \#cartel & $\begin{array}{l}\text { Number of cartel decisions: It is used as a } \\
\text { measure of the number of cartel prosecuted } \\
\text { by the CA }\end{array}$ & $\log ^{\dagger}$ & $\begin{array}{l}\text { Global Competi- } \\
\text { tion Review (GCR) } \\
\text { Enforcement Report }\end{array}$ \\
\hline age & $\begin{array}{l}\text { Number of years a country has had a cartel } \\
\text { law }\end{array}$ & Level & $\begin{array}{l}\text { Annual reports from } \\
\text { CA's website }\end{array}$ \\
\hline leniency & $\begin{array}{l}\text { Whether or not the country has a leniency } \\
\text { programme in the year } \ddagger\end{array}$ & $0 / 1$ & $\begin{array}{l}\text { Annual reports from } \\
\text { CA's website }\end{array}$ \\
\hline \#merger & Number of mergers notified to the CA & $\log$ & $\begin{array}{ll}\text { GCR } & \text { Enforcement } \\
\text { Report } & \end{array}$ \\
\hline fines & $\begin{array}{l}\text { Three-year moving average of fines (million } \\
\text { Euros)* }\end{array}$ & $\log ^{\dagger}$ & $\begin{array}{l}\text { GCR } \\
\text { Report }\end{array}$ \\
\hline prison & $\begin{array}{l}\text { Maximum number of years of imprisonment } \\
\text { for individuals found guilty of engaging in } \\
\text { cartels }\end{array}$ & $\log ^{\dagger}$ & $\begin{array}{l}\text { GCR } \\
\text { Report }\end{array}$ \\
\hline commonlaw & Civil Law $=0$, Common law $=1$ & $0 / 1$ & $\begin{array}{l}\text { Mixed jurisdictions: } \\
\text { Common law v. civil } \\
\text { law }(\text { Tetley }(1999))\end{array}$ \\
\hline prosecutorial & Integrated $=0$, Prosecutorial $=1$ & $0 / 1$ & $\begin{array}{l}\text { Design of competition } \\
\text { law institutions Fox } \\
\text { and Trebilcock }(2012)\end{array}$ \\
\hline budget & CA expenditure (millions of euros) & $\log ^{\dagger}$ & $\begin{array}{l}\text { GCR Enforcement } \\
\text { Report }\end{array}$ \\
\hline
\end{tabular}

Note: ${ }^{\dagger}$ To avoid losing observations, when the number of cartel decisions are converted in log form one is added to the value of the variable. ${ }^{\ddagger}$ An alternative measure - the number of years the CA has had a leniency policy - is infeasible given extreme multicollinearity with the age of the of the cartel law. *A three-year past moving average of fine is used, as to smooth out spikes in the data. 
Table 2: Summary statistics

\begin{tabular}{lcccccc}
\hline Variables & Obs & Mean & Median & Std. Dev. & Min & Max \\
\hline \#cartel & 300 & 11.78 & 7 & 14.17 & 1 & 91 \\
age & 306 & 39.53 & 32.50 & 25.42 & 3 & 124 \\
leniency & 306 & 8.55 & 8 & 5.87 & 0 & 37 \\
\#merger & 301 & 269.97 & 115 & 377.13 & 0 & 2231 \\
fines & 275 & 63.88 & 2 & 63.88 & 0 & 471 \\
prison & 298 & 3.28 & 2 & 3.94 & 0 & 14 \\
commonlaw & 305 & 0.27 & 0 & 0.44 & 0 & 1 \\
prosecutorial & 305 & 0.35 & 0 & 0.48 & 0 & 1 \\
budget & 294 & 2.51 & 2.39 & 1.12 & -1.39 & 4.94 \\
\hline
\end{tabular}


Table 3: Results

\begin{tabular}{|c|c|c|c|c|}
\hline Equation & Quadratic & Cubic & Quartic & $\begin{array}{l}\text { Cubic } \\
\text { without } \\
\text { budget } \\
\text { (iv) }\end{array}$ \\
\hline age & $\begin{array}{c}0.433 \\
(1.414)\end{array}$ & $\begin{array}{c}8.598^{* *} \\
(3.480)\end{array}$ & $\begin{array}{c}6.803 \\
(8.076)\end{array}$ & $\begin{array}{l}7.829 * * \\
(3.592)\end{array}$ \\
\hline $\operatorname{age}^{2}$ & $\begin{array}{c}0.729 \\
(1.253)\end{array}$ & $\begin{array}{c}-15.620^{* *} \\
(6.568)\end{array}$ & $\begin{array}{c}-9.588 \\
(25.330)\end{array}$ & $\begin{array}{l}-14.29^{* *} \\
(6.805)\end{array}$ \\
\hline $\operatorname{age}^{3}$ & & $\begin{array}{c}8.853^{* *} \\
(3.503)\end{array}$ & $\begin{array}{c}1.292 \\
(30.870)\end{array}$ & $\begin{array}{l}8.389 * * \\
(3.643)\end{array}$ \\
\hline $\operatorname{age}^{4}$ & & & $\begin{array}{c}3.082 \\
(12.500)\end{array}$ & \\
\hline leniency & $\begin{array}{c}1.444^{* *} \\
(0.684)\end{array}$ & $\begin{array}{c}1.482^{* *} \\
(0.684)\end{array}$ & $\begin{array}{c}1.483^{* *} \\
(0.683)\end{array}$ & $\begin{array}{l}1.480 * * \\
(0.686)\end{array}$ \\
\hline $\ln \#$ merger & $\begin{array}{c}0.144^{* *} \\
(0.063)\end{array}$ & $\begin{array}{c}0.135^{* *} \\
(0.061)\end{array}$ & $\begin{array}{c}0.136^{* *} \\
(0.061)\end{array}$ & $\begin{array}{l}0.150^{* *} \\
(0.062)\end{array}$ \\
\hline fines & $\begin{array}{c}-0.004^{* *} \\
(0.002)\end{array}$ & $\begin{array}{c}-0.005^{* * *} \\
(0.002)\end{array}$ & $\begin{array}{c}-0.005^{* * *} * \\
(0.002)\end{array}$ & $\begin{array}{l}-0.003^{* *} \\
(0.002)\end{array}$ \\
\hline lnprison & $\begin{array}{c}-0.142 \\
(0.108)\end{array}$ & $\begin{array}{r}-0.183^{*} \\
(0.101)\end{array}$ & $\begin{array}{r}-0.179^{*} \\
(0.103)\end{array}$ & $\begin{array}{l}-0.126 \\
(0.103)\end{array}$ \\
\hline commonlaw & $\begin{array}{c}-0.926^{* * *} \\
(0.286)\end{array}$ & $\begin{array}{c}-0.916^{* * *} \\
(0.263)\end{array}$ & $\begin{array}{c}-0.925 * * * \\
(0.267)\end{array}$ & $\begin{array}{l}-0.929^{* * *} \\
(0.274)\end{array}$ \\
\hline prosecutorial & $\begin{array}{c}0.596^{* *} \\
(0.247)\end{array}$ & $\begin{array}{c}0.470^{* *} \\
(0.232)\end{array}$ & $\begin{array}{c}0.478^{* *} \\
(0.236)\end{array}$ & $\begin{array}{l}0.406^{*} \\
(0.241)\end{array}$ \\
\hline lnbudget & $\begin{array}{l}-0.080 \\
(0.167)\end{array}$ & $\begin{array}{c}-0.079 \\
(0.167)\end{array}$ & $\begin{array}{l}-0.083 \\
(0.167)\end{array}$ & \\
\hline L1.lnbudget & $\begin{array}{c}-0.077 \\
(0.195)\end{array}$ & $\begin{array}{l}-0.043 \\
(0.194)\end{array}$ & $\begin{array}{l}-0.045 \\
(0.194)\end{array}$ & \\
\hline L2.lnbudget & $\begin{array}{c}0.367^{* *} \\
(0.148)\end{array}$ & $\begin{array}{c}0.353^{* *} \\
(0.147)\end{array}$ & $\begin{array}{c}0.354^{* *} \\
(0.147)\end{array}$ & \\
\hline$\sigma_{u}$ & $\begin{array}{c}0.458 * * * \\
(0.078)\end{array}$ & $\begin{array}{c}0.404^{* * *} \\
(0.073)\end{array}$ & $\begin{array}{c}0.407^{* * *} \\
(0.742)\end{array}$ & $\begin{array}{l}0.431^{* * *} \\
(0.074)\end{array}$ \\
\hline$\sigma_{e}$ & $\begin{array}{c}0.619 * * * \\
(0.035)\end{array}$ & $\begin{array}{c}0.620 * * * \\
(0.035)\end{array}$ & $\begin{array}{c}0.619 * * * \\
(0.035)\end{array}$ & $\begin{array}{l}0.627 * * * \\
(0.035)\end{array}$ \\
\hline Observations & 196 & 196 & 196 & 200 \\
\hline$\chi^{2}$ & $44.0^{* * *}$ & $49.9 * * *$ & $49.9^{* * *}$ & $41.2^{* * *}$ \\
\hline$\chi^{2}$ joint signif. age & $8.2^{* * *}$ & $16.3^{* * *}$ & $16.2^{* * *}$ & $17.7^{* * *}$ \\
\hline AIC & 462.1 & 458.2 & 460.2 & 467.6 \\
\hline $\mathrm{BIC}$ & 537.5 & 536.9 & 542.1 & 536.9 \\
\hline$\chi^{2}$ joint signif. cohorts & $7.8^{* * *}$ & 7.3 & $7.2^{* * *}$ & $12.2^{* * *}$ \\
\hline Cohort effects & Yes & Yes & Yes & Yes \\
\hline Time effects & Yes & Yes & Yes & Yes \\
\hline
\end{tabular}

Note: age is expressed in hundred years. Significance levels:

$* 10 \%, * * 5 \%, * * * 1 \%$. Standard errors are in parentheses. 